\title{
Implementing the Requirements of the European Flood Directive: the Case of Ungauged and Poorly Gauged Watersheds
}

\author{
S. Yannopoulos ${ }^{1} \cdot$ E. Eleftheriadou ${ }^{2} \cdot$ S. Mpouri $^{1}$ • \\ Io. Giannopoulou ${ }^{1}$
}

Received: 6 February 2015 / Accepted: 22 July 2015 / Published online: 2 August 2015

(C) Springer International Publishing Switzerland 2015

\begin{abstract}
In 2007, the European Floods Directive (FD) 2007/60/EC came into force, introducing a framework for the assessment and management of flood risks. According to Article 6 of the Directive, Member States shall prepare flood hazard maps and flood risk maps at a catchment level, covering the areas that could be flooded under different probability scenarios. The former maps include crucial information towards flood management, such as flood extent - water levels - flow velocity, that will form the base of the flood risk management plans. Based on these data, Member States shall set their objectives and prepare measures concerning their flood management plans. Hence, it is obvious that effective flood management requires reliable methods for the estimation of the flooded areas, such as precise estimation of the peak discharge. This is a hard task for hydrological engineering, taking into account that in the majority of small catchments, especially in Greece, there is a substantial lack of hydrological data. The present paper presents the effect of the uncertainty, derived from lack of data, on the estimation of the peak discharge based upon which the flooded areas will be identified. Towards this direction, a methodology of peak discharge estimation is presented in an ungauged small catchment followed by hydraulic calculations using HEC-RAS and HECGeoRAS software packages. The results demonstrate the great variability of the estimated flood extent and the effect of it on the decision-making of the proposed flood measures.
\end{abstract}

Keywords Ungauged watershed - Directive 2007/60/EC · Estimation peak discharge $\cdot$ Flood maps

S. Yannopoulos

giann@vergina.eng.auth.gr

1 Laboratory of Hydraulics Works and Environmental Management, School of Rural and Surveying Engineering, Faculty of Engineering, Aristotle University of Thessaloniki, GR-54124 Thessaloniki, Greece

2 Directorate of Environment and Spatial Planning, Region of Central Macedonia, Macedonia, Greece 


\section{Introduction}

It is considered that due to climate change, flooding events have become more frequent in the recent years. In order to face this fact, the European Union issued the Floods Directive (FD) (2007/60/EC) (Council of the European Communities 2007), as a tool to assist Member States to manage the floods effectively. Each member should comply with the requirements as set in the Directive and achieve certain goals within a strict timeline.

The Floods Directive 2007/60 entered into force in November 2007 and since then it provides a complementary part of the Water Framework Directive (WFD) 2000/60/EC, concerning flood issues. Its primary goal is to enact a framework for the assessment and the management of flood risks targeting at the reduction of the negative effects on human health, the environment, the cultural heritage and economic activities that are connected with floods (Article 1).

Effective flood management is achieved through the detailed knowledge of the hazards and risks that exist in a particular area. In order to organize this crucial data, flood maps are indispensable tools to show information about hazards, vulnerabilities and risks in a particular area (EXCIMAP 2007). Moreover, the geographical identification of areas at different level of risk through flood mapping, make the information more transparent and easily accessible to the public. Flood mapping plays a crucial role on the understanding of flood risks and provides a reliable base upon which each Member State will decide on their actions to avoid, mitigate, transfer, share, or accept the risks. According to Tsakiris et al. (2009), a good starting point for the preparation of flood risk maps is the confirmation of the safety standards by different authorities (state, regional or local), and also considering different safety standards for different causes of flooding, facilitates flood risk management, where the term "safety standard" means the exceedance frequency of water level. The FD only mentions (Article 6) three probabilities of flooding (high, medium and low) and it leaves the choice of the flood exceedance frequency of water level (safety standard) to Member States. In our view, an in depth analysis concerning the flood risk issues is required, regarding safety standards and approaches, and mainly, whether these should be set out at the EU level or at a national, regional and river basin level. Concerning the identification of these measures, the FD renders responsible each Member State by stating "detailed objectives for protection against floods, measures best suited to achieve the objectives and deadlines will not be defined at EU level" (COM 2006).

A reality that often has to be faced by Member States, especially when dealing with small catchments, is the lack of hydrologic data that is essential for the subsequent flood mapping. Especially in Greece, where the majority of the country's territory comprises small ungauged and poorly gauged watersheds, flood estimation and design of proposed flood prevention schemes is a hard task. Moreover, many methods often used (such as SCS-CN), are based on field data from few experimental catchments and are not updated nor validated, affecting the cost and safety of flood protection works (Efstratiadis et al. 2013).

In the present paper, the case of a small ungauged watershed in North Greece (Tourla watershed) is investigated, in relation to the estimation of the peak flow using a set of various methodologies. The results of the hydrologic calculations of all the methods are then introduced in the hydraulic model HEC-RAS, in order to demonstrate the effect of the uncertainty characterising ungauged watersheds on flood mapping. Flood hazard maps should include data for three scenarios of flooding (low-medium-high probability), but in the current study only the high probability is demonstrated, as the Greek technical specifications were applied, where the return period when designing flood prevention works should be set to 50 years. 


\section{Legislation}

The proposition for the preparation of a European Directive for the management of floods was first mentioned in the Floods Action Programme prepared by the European Commission. The first draft of the FD was released in January 2006 after a public consultation. The negotiations of the Member States concluded unanimously in the final text of the Directive on 27 June 2006, that was later adopted as Common Position of the Council on 18 October 2006. Directive 2007/60 entered into force in November 2007 and since then it provides a complementary part of the WFD concerning flood issues.

The most important elements of Directive 2007/60 are:

- Framework on the assessment and management of flood risks.

- Preliminary flood risk assessment based on available information and experience from past floods concluding in predictions of future floods and identification areas of potential significant flood risk.

- Flood mapping: flood hazard maps and flood risk maps according to different scenarios (low - medium - high probability).

- Establishment of Flood Risk Management Plans, where the Member States shall establish appropriate objectives focusing on the reduction of adverse consequences of flooding for human health, the environment, cultural heritage and economic activities.

- The encouragement for the establishment of an international flood risk management plan or a set of plans coordinated at an international catchment level.

- Member States shall coordinate the implementation of the FD Directive with Directive 2000/60. Both river basin and flood risk management plans are fundamental for the integrated basin management and thus every possibility of synergy between them should be exploited.

- The active involvement of all interested parties is pursued and coordinated with article 10 of Directive 2000/60.

In 2010, the FD was introduced in the Greek legislation with a Common Ministerial Decision (2010) and in December 2012 the report of the preliminary flood risk assessment was issued, according to Article 4 of the FD. The report included maps of all the river basin districts, data collection of historic floods and identification of those with significant adverse impact, taking into account any human losses, the compensation provided and the flooded area (Special Secretariat for Water 2012).

The main types of flood maps introduced by the FD are flood hazard and flood risk maps, where the former contain information on the probability and magnitude of flooding and the latter incorporates the consequences of flooding. Flood extent maps are the most widespread flood maps, followed by flood depth maps, sometimes velocity and rarely propagation (de Moel 2009). Flood hazard maps include crucial information towards flood management, such as flood extent - water levels - flow velocity, that will form the base of the flood risk management plans. Based on these data, Member States shall set their objectives and prepare measures concerning their flood management plans.

The European Commission, acknowledging the importance of the preparation of reliable flood maps, issued in 2007 the "Handbook on good practices for flood mapping in Europe" (EXCIMAP 2007). According to this document, flood maps form the basis for the management of flood risks and they form a prerequisite for achieving effective and efficient flood 
management. The status of flood mapping in Europe is described in a document prepared for the 2015 EU Water Conference (European Commission 2014), reporting on the progress of Member States on flood mapping by December 2014, where information is missing from Bulgaria, Greece, Malta and Portugal.

The subsequent step of flood risk mapping varies from the flood hazard mapping, as it incorporates more indicators for the assessment of flood consequences compared to the few indicators used during flood hazard estimation (de Moel 2009). Moreover, flood risk mapping is highly affected by the questions that have to be addressed. According to FD: "Flood risk is the combination of the probability of a flood event and of the potential adverse consequences to human health, the environment and economic activity associated with a flood event'. Risk does not remain constant in time, as the vulnerability parameters (such as population, assets and economic activity) may change rapidly, and it is often necessary to predict changes in risk in the future, to make better decisions (Handbook on Good Practices 2007). Flood risk maps are qualitative maps, which show the indicative number of inhabitants potentially affected, the type of economic activity affected such as installations (industrial activities) of Annex I of the Directive 96/61/EC and the protected areas of Annex IV of the WFD. The level of detail and the type of information depicted on the maps can be decided upon the special features of the area under study and any particular interest of the Member State (e.g., distribution of particular vulnerable groups or affected installations causing pollution).

Flood Risk Maps play an important role in the decision-making process, as it identifies the areas where the greatest risk exist and sets the priorities concerning the planning of the flood protection measures. Moreover, such maps can support the decision-makers with the selection of the best combination of measures, the designation of flood warning systems and even with the management emergency situations and crisis management (Handbook on Good Practices 2007). Hence, the identification of the flooded areas (flood extent, water depth), during the precedent process of flood hazard mapping, forms the basis for the subsequent requirements of the FD, as it affects directly the preparation of flood risk maps and consequently the Flood Risk Management Plans.

\section{Methodology}

\subsection{Introduction}

In the current study, a set of various methodologies of hydrograph estimation are presented and compared in order to investigate the variations of the peak discharge and examine which factors affect and at what level the produced results. A similar study by Yannopoulos et al. (2012), showed great variations of the produced design hydrographs, especially on their geometric characteristics, where four different statistical models were used for the Intensity-Duration-Frequency (I-D-F) relationship. In the present study, the I-D-F equation was derived at an adjacent station (Papamichail and Georgiou 1999). In order to transfer information between watersheds or even between regions, climatic, geologic and geomorphologic homogeneity between the watersheds or the regions are needed (Brass 1990). According to Pilgrim and Cordery (1993), "this highlights the danger of transposing procedures and design information from one country or region to another and reinforces the need for the derivation of procedures and parameters from observed data in each region". To the extent that we 
keep in mind, there are not such conditions in the wider region of the study area nor simultaneous rainfall-runoff measurements.

In another study by Yannopoulos et al. (2014), the effects of the Synthetic Unit Hydrograph (SUH) selected (SCS and Sierra Nevada SUHs) and the storm distribution method on the hydrographs produced, demonstrate substantial differences on peak discharge and time of peak. Thus, the selection of the most appropriate methodology forms a crucial step in flood studies, as the proposed flood protection works are designed based on the predicted water level that corresponds to the estimated peak discharge, and consequently, any uncertainty in the estimation procedure affects directly the cost effective design of the flood protection works.

The standing technical specifications in Greece (Presidential Decree 696/1974, Articles 177-194) concern design of hydraulic works and mainly irrigation projects (Article $177 \S 1$ ), but they can be applied also in hydrological studies after the necessary amendments are made (Article 194). As far as it concerns the issue of design flood flows, certain methods can be used depending on the nature and the importance of the projects under study. According to the legal instructions, the following calculation methods can be applied:

Empirical methods of estimating maximum flood flow.

Statistical methods based on the statistical processing of flow and water stage measurements in order to extend their application in cases of higher return periods.

The Rational Method.

Time - Area method.

Hydro-meteorological methods such as the unit hydrograph method or use of precipitation data from adjacent watersheds under similar hydrologic conditions.

Eight cases were investigated in the current study, in order to estimate the effect of each method on the outcome concerning peak discharge, time to peak and total flood volume. As shown in Table 1, each case is characterised by a specific storm duration, a storm distribution (Alternating Block Method and SCS method for type I and IA) and a SUH (SCS and Sierra Nevada).

Table 1 The eight cases investigated

\begin{tabular}{|c|c|c|c|c|c|c|c|}
\hline \multirow[t]{2}{*}{ Case } & \multicolumn{3}{|c|}{ Storm Duration (hrs) } & \multicolumn{2}{|l|}{ Storm Distribution } & \multicolumn{2}{|c|}{ S.U.H. } \\
\hline & 6 & 12 & 24 & Alternating Block Method & SCS & SCS & Sierra Nevada \\
\hline A & $\sqrt{ }$ & $\sqrt{ }$ & $\sqrt{ }$ & $\sqrt{ }$ & & $\sqrt{ }$ & \\
\hline $\mathrm{B}$ & $\sqrt{ }$ & $\sqrt{ }$ & $\sqrt{ }$ & $\sqrt{ }$ & & & $\sqrt{ }$ \\
\hline $\mathrm{C}$ & $\sqrt{ }$ & & & & $\sqrt{ }$ & $\sqrt{ }$ & \\
\hline $\mathrm{D}$ & $\sqrt{ }$ & & & & $\sqrt{ }$ & & $\sqrt{ }$ \\
\hline $\mathrm{E}$ & & & $\sqrt{ }$ & & $\sqrt{ }(\mathrm{I})$ & $\sqrt{ }$ & \\
\hline $\mathrm{F}$ & & & $\sqrt{ }$ & & $\sqrt{ }(\mathrm{IA})$ & $\sqrt{ }$ & \\
\hline G & & & $\sqrt{ }$ & & $\sqrt{ }(\mathrm{I})$ & & $\sqrt{ }$ \\
\hline $\mathrm{H}$ & & & $\sqrt{ }$ & & $\sqrt{ }(\mathrm{IA})$ & & $\sqrt{ }$ \\
\hline
\end{tabular}




\subsection{Design Flood Hydrographs}

According to Westphal (2001) "when watersheds are large, that is, when they are comprised of two or more smaller watersheds whose streamflow at the confluence with common collector channel can be expected to be displaced in time, where storage influences the time distribution of flow in a stream, or where storage is a part of the design problem, peak flow methods are inappropriate for hydrologic design. In these instances, it is necessary to estimate the entire flow hydrograph." In the current study the produced design flood hydrographs from different methods are investigated, in order to compare not only peak flows, but also all geometric characteristics that are affected by the various methodologies.

\subsubsection{Estimation of the Design Hyetograph}

Return Period The choice of the return period of the design flow is of paramount importance and it depends on various factors such as the size of the watershed, the accepted failure risk and the type of the designed structure. In practice, for small watersheds short return periods are selected whereas long ones are selected in the case of structures such as levees (between 50 and 100 years). As a rule of thumb, in areas where no direct risk on properties exist, a return period of 50 years is considered safe, where in areas with human population the return period should be increased at 100 or 200 years.

It is obvious that increasing return period represents an increase on project costs, but on the other hand reduces the potential damage from any construction failure. The optimal return period can be derived by optimizing the sum of the construction costs and the cost of the remediation works. In practice, it is almost impossible to quantify the amount of damages, so the choice of return period in Greece follows in general the following principles (Ministry of Environment 2002a): i) for storm sewers in residential areas: $T=2$ to 15 years (most frequent value is 5 years); ii) for storm sewers in commercial areas and for central sewer collectors: $T=10$ to 15 years; iii) for flood control projects and settlement on watercourses: $T=50$ years and more.

In cases of constructions near watercourses (bridges, culverts), it is necessary to estimate the design flood hydrograph, which is connected directly with the design storm. In general, the return period of a design storm does not coincide with the return period of the corresponding flood design (e.g., flood peak), mainly due to the impact of hydrological losses (retention, infiltration, etc.) that may differ during each storm. According to the Ministry of Environment (2002b), it is preferable to settle the return period of the design storm from the return period of flood, since it is more usually met that rainfall data covers long time periods and present more complete records, even in cases where water flow measurements do exist.

According to Larson and Reich (1973), this differentiation between the return period of the design flood and the design storm is not appropriate, since on average the two periods coincide. Moreover, Koutsoyiannis (2004) argues that such a distinction should not be taken into account. In the present study, the return period of the design storm was calculated from the one of the design flood according to Sutcliffe (1978). Thus, a return period of 50 years was selected based on the nature of the project under study -river bounding- that corresponds to a return period of 81 years design storm.

Storm Duration Defining storm duration is a crucial step of the peak discharge estimation process. As a general rule, the duration of the design storm should be at least equal to the time 
of concentration in order to be able to calculate peak discharge (Westphal 2001). Usually, the duration is taken as multiple of 3 or $6 \mathrm{~h}$. In order to select the most appropriate duration, several trials should be made in order to choose the one that leads to the worst outcome. However, as shown by the analysis hydrographs, increased flood peak appears usually for short durations (short duration corresponds to a large volume). In general, a few tests should be always run in order to determine the duration of the design rainfall (Tsakiris 1995).

According to Tsakiris (1995), for projects as drainage networks and storage projects (e.g., dams) in small watersheds, the hydraulic calculations should be realized for rainfall durations less than $3 \mathrm{~h}$. Likewise, for large storage projects or for major flood control projects longer rainfall durations should be applied (e.g., 6, 12, 18 and 24 h). In the latter case, special attention must be drawn on the temporal distribution of rainfall considered.

According to the Greek Ministry of Environment (2002b), rainfalls lasting $24 \mathrm{~h}$ is a reasonable choice for catchments where rainfall duration is longer than the time of concentration. It should be noted that during the process of determining the design storm, the storm duration should be taken as a significant multiple (well over double) of the watershed's lag time. The latter view was followed in the present study.

Rainfall Distribution Estimating the design flood while considering constant rain intensity throughout its duration could easily lead to false conclusions, as rainfalls with duration of a few hours are considered too long to assume that the intensity remains constant. From the literature it is shown that the temporal distribution of rainfall is important for the resulting flood hydrograph. Indeed, two storms with the same depth but with different distribution for the same duration produce different flood hydrographs.

According to McCuen (1998): "for many problems in hydrologic design it is necessary to show the variation of the rainfall volume with time. That is, some hydrologic design problems require the storm input to the design method to be expressed as a hyetograph and not just as a total volume of the storm".

Three methods were applied in the current study for the calculation of the storm distribution; i) the Soil Conservation Service (SCS) method for storm duration of $6 \mathrm{~h}$ (SCS 1972), ii) the Soil Conservation Service, for storm type I and IA of $24 \mathrm{~h}$ duration and iii) the Alternating Block Method (ABM) for storm durations of 6, 12 and $24 \mathrm{~h}$ (Chow et al. 1988). Obviously, the SCS method was developed for conditions met in the USA, while there is no bibliographic reference that examines which storm types may be applicable to the Greek conditions. For this reason, and due to lack of data, methods i) and ii) were not evaluated further in the present study.

Rainfall Depth Proper design of water resources projects is highly based on the Intensity - Duration - Frequency relationships that are extracted from historic data of extreme rainfalls of different durations, while the return periods used should be equal to the economic projects' life. Estimating the maximum rainfall intensity $(i)$ for various durations $(t)$ and for various return periods $(T)$ is achieved through the frequency analysis of extreme values. The maximum values of rainfall intensity normally follow a frequency distribution of extreme values, which is not easy to define. Various applications of distributions have been observed over time. In the current study four statistical distribution models are applied; Gumbel, Pearson III, Pearson III using the frequency factor and log-Pearson III. The assessment of rainfall losses and consequently of the effective rain was realized by the method of the runoff coefficient CN of the SCS method. 
Rainfall data is taken by a meteorological station installed in an adjacent catchment area, where the I-D-F relationships and the corresponding coefficient of determination, $R^{2}$, have been derived by Papamichail and Georgiou (1999). Equation (1) is based on Gumbel distribution with a high coefficient of determination $R^{2}=0.9636$, and thus, it is considered that it represents quite satisfactorily the frequency of the maximum annual rainfall values observed in the area (as registered at the local meteorological station 'Megali Panagia').

$$
\text { Gumbel : } \quad i=\frac{20,5069 T^{0,1613}}{t^{0,64}} \quad R^{2}=0.9636
$$

\subsubsection{Determination of the Synthetic Unit Hydrograph}

In the absence of appropriate measurements of runoff and rainfall, the unit hydrograph can be calculated using the geometric characteristics of the watershed under study. The most popular SUH is the one developed by the Soil Conservation Service (SCS), which was used in the current study and was compared with the Sierra Nevada SUH as described in the Design of Small Dams (U.S.B.R. 1987).

\subsection{The Study Area}

The study area is situated in the southern part of Sithonia Peninsula at Chalkidiki region in Northern Greece. The land cover is characterized by mountainous and hilly areas, covered with low vegetation and pine forests. The climatological conditions are representative of the typical Mediterranean climate due to the ground relief and the vicinity of the area to the sea. The mean annual precipitation is $477.9 \mathrm{~mm}$, whereas precipitation records show that high values are observed during the period of 1 day, with the observed maximum value taken place in June 1975 reaching $90.3 \mathrm{~mm}$ (Mpouri 2008). High values of precipitation are observed in May where the mean monthly value is estimated at $61.4 \mathrm{~mm}$, while the lowest values occur in August (16.2 mm mean value) (Fig. 1).
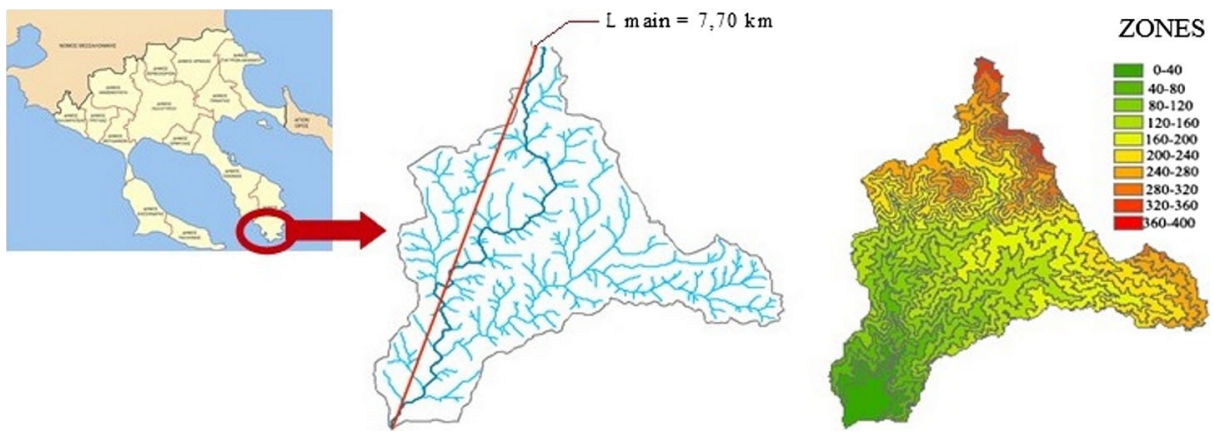

Fig. 1 The study area of Tourla watershed 


\subsection{The Hydraulic Model}

The hydraulic modelling of the case study (Tourla watershed) was realised using initially the HEC-GeoRAS software developed by U.S. Army Corps of Engineers, in order to import the geometric characteristics of the basin. The GIS data was then imported in HEC-RAS software developed by U.S. Army Corps of Engineers as well, in order to simulate the flood flows. In this stage, it was found out that the DEM of the watershed was not sufficient for the detailed mapping of the stream course. In order to tackle this issue, it was decided to use 18 cross sections that were derived from in-situ measurements and were provided to the authors by a private company. The boundary conditions were set as known water surface. For the upstream boundary the critical depth was mathematically calculated (Eq. 2) according to Chanson (1999), whereas the downstream boundary was set at the sea level $(0 \mathrm{~m})$. It is noted that the upstream cross section is considered as a triangular shape. The one-dimensional numerical simulation was run for unsteady flow and mixed flow conditions for all the hydrographs that were produced by all the methods.

$$
y_{c}=\left(\frac{2 Q^{2}}{g m^{2}}\right)^{0.2}
$$

\section{Results}

\subsection{Design Flood Hydrograph for Rainfall Distribution of ABM}

The ABM provides a simple way to distribute the rainfall by placing the peak of the hyetograph at the middle of the storm duration. Initially, the rainfall intensities were calculated using four different I-D-F curves for design flood return period of 50 years, that corresponds to design rain return period of 81 years (Sutcliffe 1978), and for rain durations of 6, 12 and $24 \mathrm{~h}$. Based on the results, the corresponding depths of the total effective rain were estimated from the equation $h=$ i.t (where i: intensity and t: storm duration). The resulting hyetographs are shown in Fig. 2.

The unit hydrograph is determined on the basis of the peak discharge, $Q_{p}$, the time to peak, $t_{p}$, and the dimensionless parameters of time and direct runoff $\left(t_{a}, Q_{a}\right)$. Two cases were investigated and compared, the SUH of the SCS method and the SUH of Sierra Nevada. Figure 3 demonstrates that the SUH of the SCS method produces greater peak values in a shorter time compared with the corresponding values derived from the Sierra Nevada U.H. Also, the analysis of the above SUHs shows a higher peak flow for the design storm of $0.50 \mathrm{~h}$. In particular, for the rain of $0.50 \mathrm{~h}$, the peak flow deviation deriving from the two SUHs is $23 \%$, while for the time to peak is around $120 \%$. The discrepancies observed in the results are due to the diversity of the assumptions combined with the dimensionless unit hydrographs that were used in each SUH method.

The Design Flood Hydrographs derived using the ABM method and for the design storms of 6,12 and $24 \mathrm{~h}$ and for 50 years return period were calculated based on the principles of proportionality and superposition and are depicted in Figs. 5, 6 and 7.

\subsection{Design Flood Hydrograph for Rainfall Distribution SCS}

The SCS method has developed four storm types (I, IA, II, III) for storm duration of $24 \mathrm{~h}$ and one type for storms of $6 \mathrm{~h}$ duration. Concerning Greece, there is lack of a systematic study that 


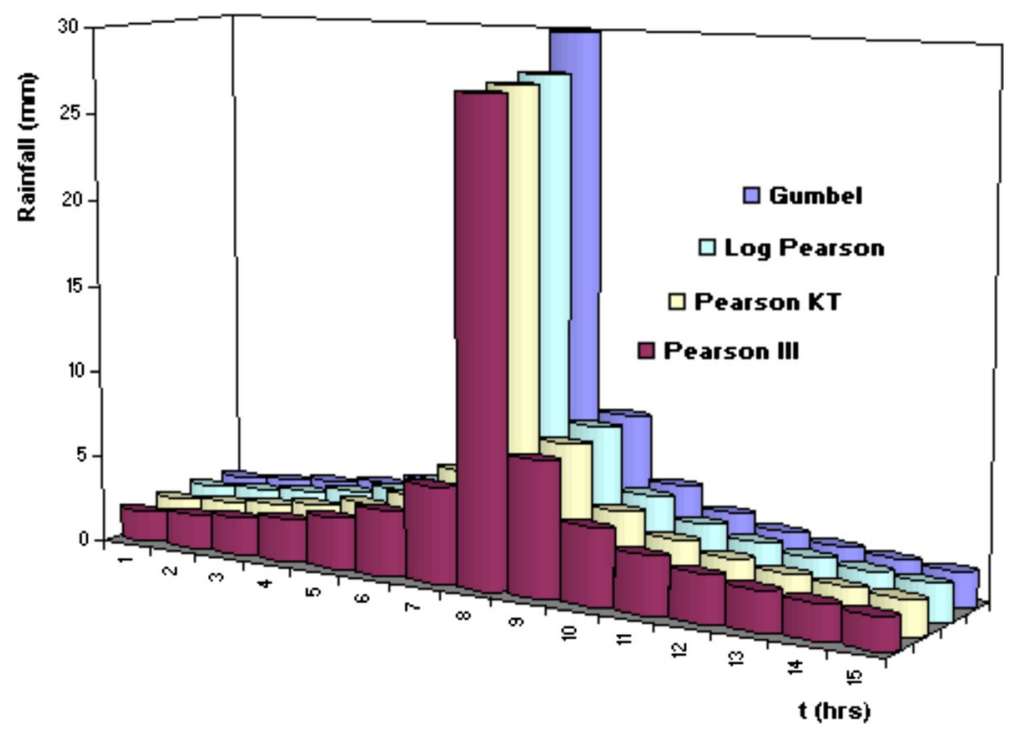

Fig. 2 Synthetic hyetographs using the ABM for storm duration $6 \mathrm{~h}$ for four I-D-F curves

would adjust the storm types to the local climatic and environmental conditions. The selection of the storm types applied in the current study is based on Daniil et al. (2005), where types I and IA were used corresponding to wet winters and dry summers, while the produced design hyetographs are shown in Fig. 4. The produced Design Flood Hydrographs are shown in Figs. 5, 6 and 7 .

\subsection{Comparison of Results}

\subsubsection{Hydrologic Calculations}

In the present study, the variation of the peak flow values of a small watershed in Northern Greece is investigated, where there is lack of data as in the majority of similar cases. For this purpose, empirical equations and methods were used as described in the Greek specifications along with more theoretical methods, such as the SCS methods and the Sierra Nevada SUHs.

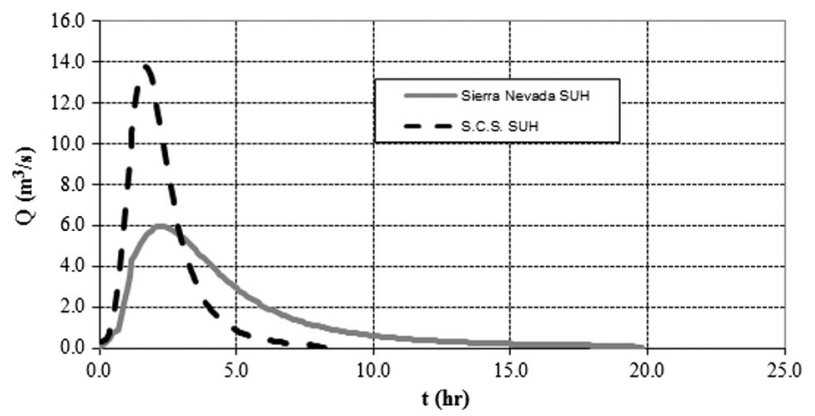

Fig. 3 SUH of SCS method and Sierra Nevada for storm duration $0.5 \mathrm{~h}$ 


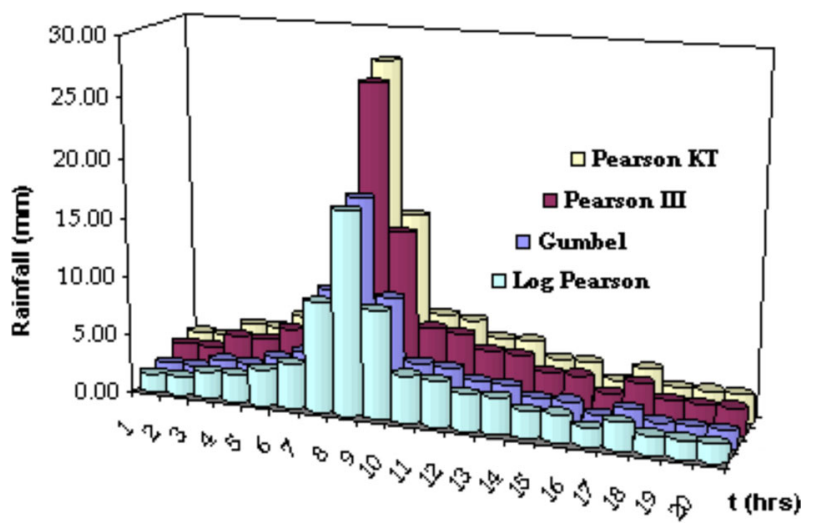

Fig. 4 Synthetic hyetographs of the SCS distribution for storm duration of $6 \mathrm{~h}$ and four I-D-F curves

The resulted design hydrographs from the hydrologic calculations prove that there is great uncertainty of the computed peak discharge, steaming from the selected method applied. High variations of peak values and time of peak are observed for all the cases investigated (different storm duration, storm distribution and SUH method).

By comparing the results of the eight cases as presented in Table 1, it can be concluded that:

a. The type of the SUH selected affects greatly the peak flow and the corresponding time to peak, while the flood volume is only slightly affected for all the storm durations that were applied.

b. The resulting flood hydrographs for storms lasting $24 \mathrm{~h}$ (Fig. 7 - Cases E-F and G-H), which are calculated using the same SUH method but different type of storm (I or IA) produce peak flows with differences ranging to $30 \%$, much less variation for the time to peak and almost none for the flood volume.

c. It is concluded that the SUH used in each case affects significantly the geometric characteristics (peak flow variation around $40 \%$ and time of peak $17 \%$ ) of the flood hydrographs, due to the assumptions introduced in the methodologies of the SCS and the

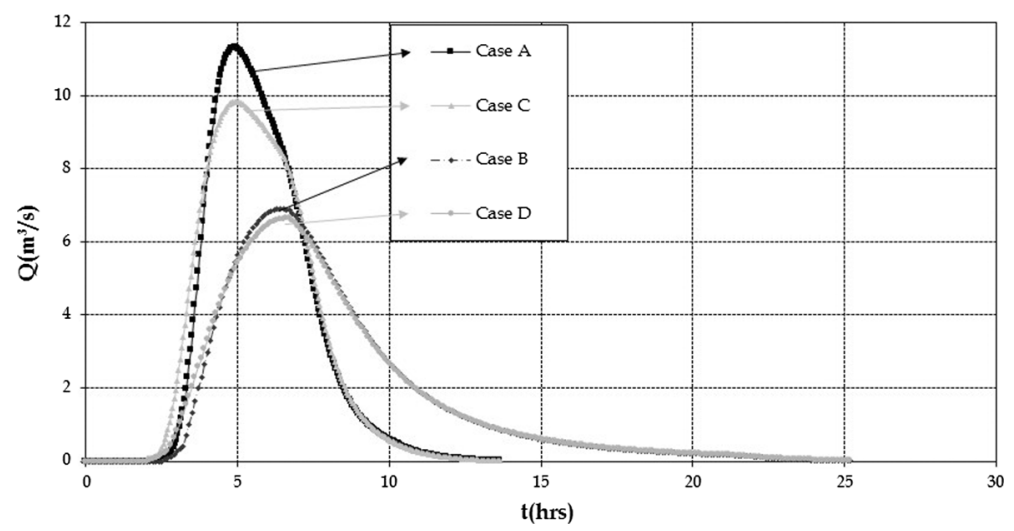

Fig. 5 Design hydrographs for storm duration of $6 \mathrm{~h}$ for Cases A, B, C and D 


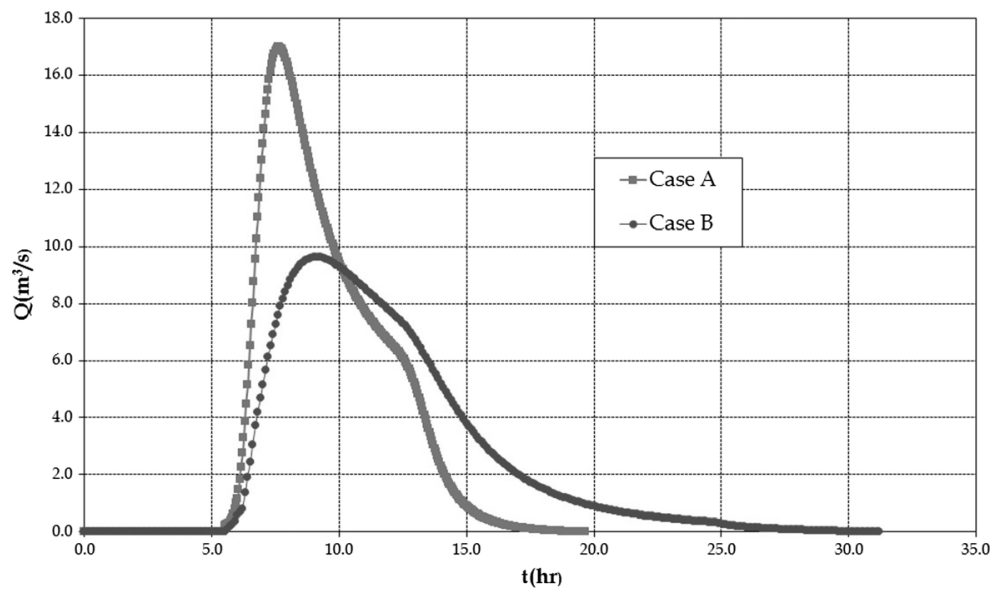

Fig. 6 Design Hydrographs for storm duration of $12 \mathrm{~h}$ for Cases A and B

Sierra Nevada SUH (Fig. 5), while the method of the storm distribution does not cause that significant changes in the hydrographs.

d. The hydrographs of Cases A and E give the highest peak flow values, while variations of the time of peak are observed for all cases (Fig. 7). Comparing the distribution of storm type I and IA, it is concluded that the peak value of type I rainfall occurs between 11 and $12 \mathrm{~h}$, while for type IA during 9-10 h. The results show that the selection of the storm distribution of the design rainfall plays a crucial role in the determination of the design flood hydrograph

e. When comparing the two SUHs applied, it is concluded that the SCS method produces higher peak values than the Sierra Nevada one (as in Fig. 6).

It is clear from Fig. 5 that the higher values of peak flows are observed in the case of the SCS SUH combined with the ABM for storm distribution (Case A), while lower peak values are predicted by the Sierra Nevada SUH combined with the SCS storm distribution (Case D). Deviations of peak flows for Cases A and B amount up to $40 \%$, while similar findings are attributed to time to peak and total flood volume. As for the time to peak, Case C estimates

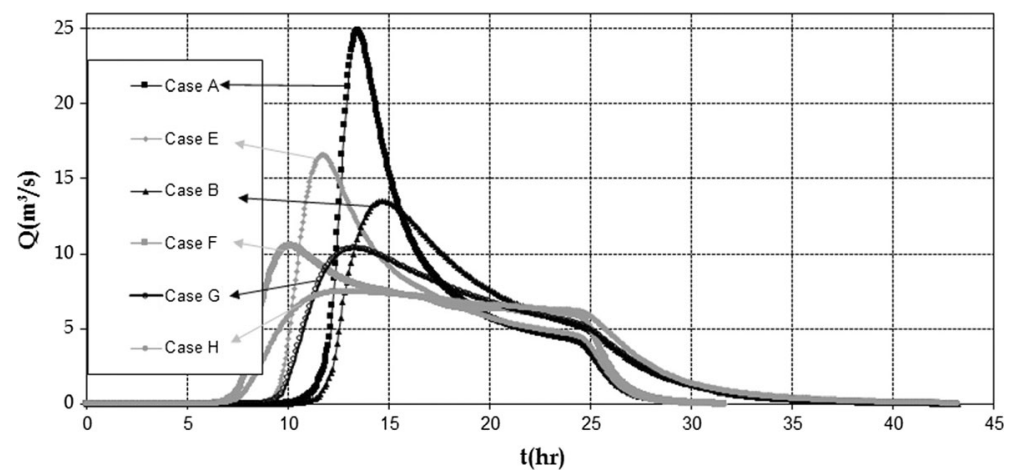

Fig. 7 Design hydrographs for storm duration of $24 \mathrm{~h}$ for Cases A, B, E, F, G and H 
lower values compared to Cases A, B and D. It should be noted that for all Cases the volume deviations are negligible.

The impact of each selected methodology is illustrated in Figs. 6 and 7 where the hydrographs of the rain of $12 \mathrm{~h}$ and $24 \mathrm{~h}$ are illustrated. The design hydrographs when applying different SUH methods, vary significantly (Fig. 6) concerning their geometric characteristics, the peak flow (maximum deviation around $48 \%$ ) and time to peak (maximum deviation approximately $16 \%$ ). As shown in Fig. 7, where the methods of SCS and Sierra Nevada S.U.H. are applied, the combined effect of changing both storm distribution and the SUH method is higher for the peak flow (reaches up to $70 \%$ ).

The results show that the selection of the storm distribution, storm duration and SUH method, play a crucial role in the determination of the design flood hydrograph. Moreover, concerning any uncertainty derived by the use of the I-D-F curves, it would be extremely useful that I-D-F curves are estimated for each catchment of Greece by a central authority that could function in an independent status and probably under the supervision of the Ministry of Environment.

\subsubsection{Hydraulic Model}

At a next stage, the produced hydrographs are inserted in the hydraulic model and after running the model for unsteady-state flow conditions, the variation on the flooded area for each case investigated is depicted clearly, as shown in Fig. 8 in the 3D plot of the water lever at each cross section. Figure 9 provides a more detailed view of the flooded areas in two parts of the stream, where it is shown that hydrographs of Case A and Case $\mathrm{H}$ (the two cases where the highest and the lowest peak discharge is observed), present high variances of the affected areas. By comparing the results of these two extreme cases, it is observed that "Flow Area" can vary up to $84.7 \%$, "Water level" up to $44.4 \%$, "Top Width" up to $85.9 \%$ and "Velocity" values may differ more than $100 \%$.

For instance, as shown in the following Fig. 9, top width of the inundated area can vary from 45.26 to $11.15 \mathrm{~m}$ at cross section 18 , while at the residential area further downstream (at cross section 8), variations range from 33.23 to $12.47 \mathrm{~m}$. It is obvious that these variations can be misleading, when investigating the effects of a flood or when estimating economic figures

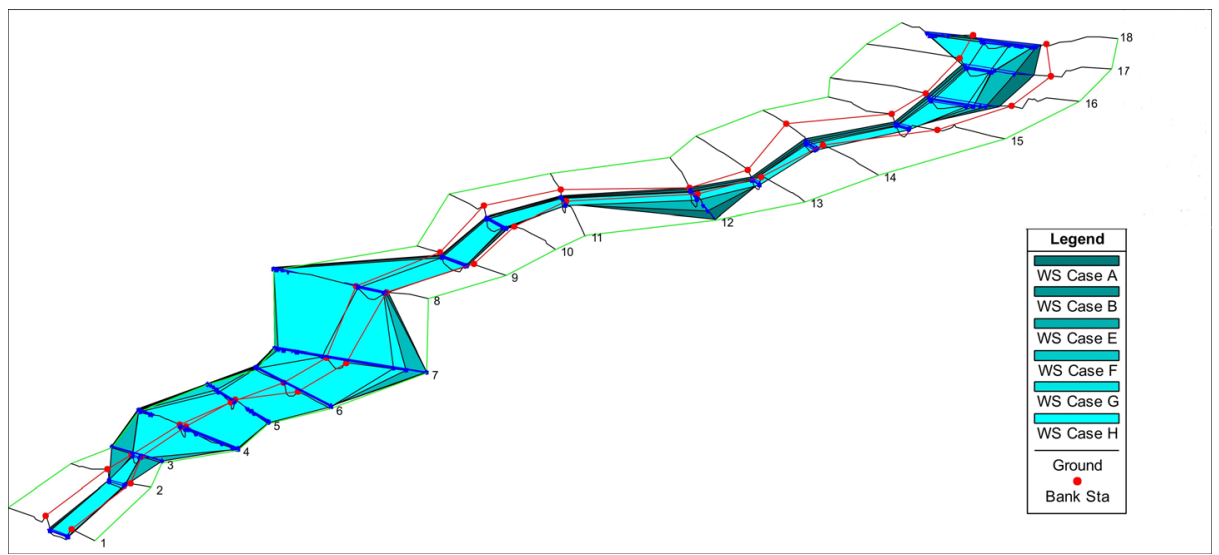

Fig. 8 Flooded areas for different cases 
(such as cost of flooding during a cost-benefit analysis), either on a rural or an urban area. In addition to this, the differences observed in the velocity values, could affect the hydraulic calculations concerning the estimation of sediment transport in the channel.

Based on the results of the hydraulic model, flood protection works can be proposed at each cross section, such as cross section widening and levee construction where suitable, as in the downstream part building structures adjacent to the watercourse confine the selection of flood measures. By analyzing the results of the water profile, certain flood measures are proposed for each part of the stream. Stream-bed settlement and cross section widening are applied in all cross sections in order to increase the flow capacity, whereas widening of the downstream sections is limited due to the expansion of the residential area. In Fig. 10, the effect of the flood protection works are shown for Cross section 6, which is situated at the downstream part of the watershed. As shown, concerning Case A, in order to prevent the adjacent area of flooding, levees of $0.5 \mathrm{~m}$ height should be constructed, while the water level of Case $\mathrm{H}$ is well below the embankment and hence no flood measure is needed. The above remark proves the necessity of implementing reliable methods when estimating the input hydrographs in a model, as the engineer could be misguided and propose unrealistic flood measures.

\section{Conclusions}

In the present study, the design hydrographs of an ungauged small watershed were estimated for different storm durations and distributions, combined with two different SUHs. The results show that peak discharges are highly affected by the methods selected for all the above parameters. The return period of 50 years remained constant in all the calculations as it is considered a safe choice for river bounding in a non-residential area. The engineers should pay great attention to the methodology followed and especially to the use of empirical methods, even if they are stated in the Greek specifications, as they should be applied with great caution due to the great variability of the resulting peak discharge. A comparison of a number of selected methods prior to the decision-making phase, could be proven useful, as it would provide the engineers with a variability of results, in order to choose the most appropriate ones in relation to the flood prone area and the designed flood protection measures.

The hydrological analysis demonstrated that the selected methodology of the storm distribution plays a crucial role in the identification of the design hydrograph. For example, type I storm distribution generates a hyetograph with a peak value at 9-10 $\mathrm{h}$, while for type IA the peak is

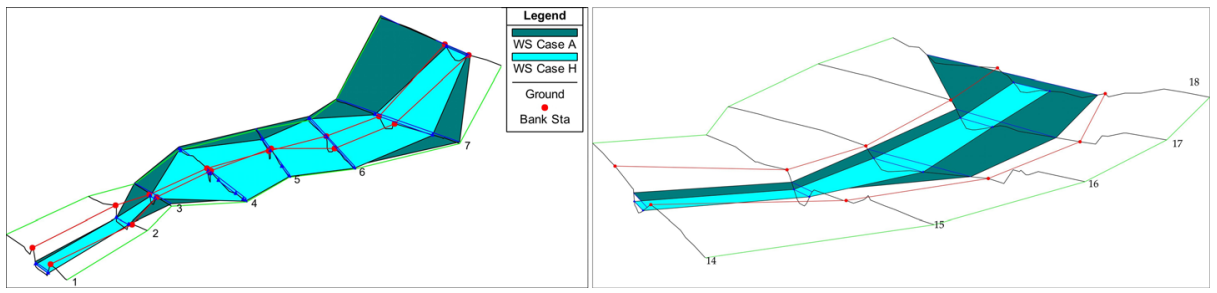

Fig. 9 Details of Fig. 8 

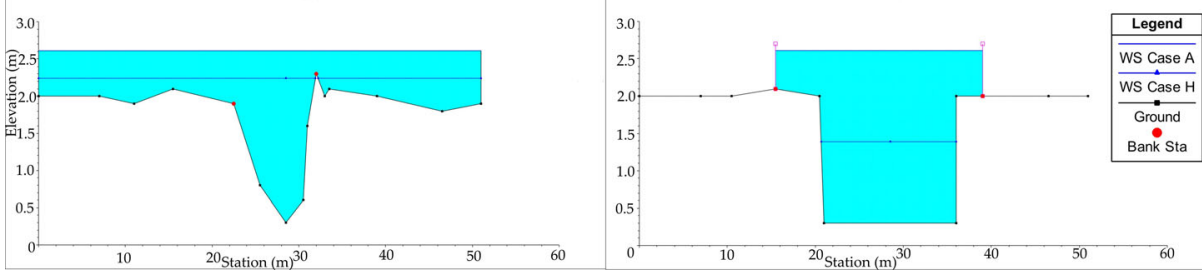

Fig. 10 a Cross section 6 before; $\mathbf{b}$ after the flood protection works for the two extremes peak discharges (Case A and Case $\mathrm{H}$ )

observed at $7-8 \mathrm{~h}$ and for the ABM method at $11-12 \mathrm{~h}$. Hence, it is obvious that the selection of the storm distribution method, affects directly the time period of the peak value. In practice, more simplified methods are preferred (Westphal 2001), such as the ABM, while others based on nondimensional time distribution are considered as arbitrary (Koutsoyiannis 2004).

The ABM presents certain advantages compared to the other bibliographic methods, such as:

- It is based strictly on data of the study area (rainfall intensity curves) rather than on diagrams or tables of the bibliography.

- It produces a single design hydrograph with no further assumptions.

- The produced results seem more reasonable than the ones produced from the other methods.

However, the basic disadvantage of this particular method is the fact that for each time step, the corresponding rainfall depth has the same return period with the total rainfall depth.

Concerning flood management, the lack of rainfall-runoff data causes many impediments to the country's compliance with the FD's requirements. The preparation of flood hazard maps that were completed in March 2014, should have been based on well-structured models, as the results produced (flood extent, water depths and flow velocity), will form the basis of the flood protection management plans as described in Chapter IV of the FD. This is a highly important procedure as these plans will include measures focusing on the reduction of potential adverse consequences of flooding for human health, the environment, cultural heritage and economic activity. Hence, the construction of cost effective flood prevention schemes directly depends on the reliability of these plans.

The preparation of flood hazard maps is not the endpoint of the implementation of the FD. The subsequent step of the preparation of flood risk maps contains many issues to be addressed, such as the definition of risk which may vary greatly among different case studies. Moreover, the interpretation of the above maps will form the base of the Flood Risk Management Plans, where the proposed measures and preparedness against flooding shall be addressed. Hence, the starting point of all these procedures, i.e., the reliable estimation of hydrologic conditions, forms a crucial point in the successful implementation of the FD across Europe.

Acknowledgments An initial version of this paper has been presented in the 12th International Conference on Protection and Restoration of the Environment, Skiathos Island, Greece, June 29 to July 3, 2014. 


\section{References}

Brass RL (1990) Hydrology: an introduction to hydrologic science. Addison-Wesley Publishimg Company, Reading

Chanson H (1999) The hydraulics of open channel flow: an introduction. basic principles, sediment motion, hydraulic modelling, design of hydraulic structures. Wiley, New York

Chow VT, Maidment DR, Mays LW (1988) Applied hydrology. McGraw-Hill, New York

COM (Commission of the European Community) (2006) Proposal for a directive of the European parliament and the council on the assessment and management of floods. COM(2006)15 final of 18.1.2006

Common Ministerial Decision No. 31822/1542/E103 (2010) Assessment and Management of Flood Risks in compliance with Directive 2007/60/EC of the European Parliament and of the Council of 23 October 2007. Greek Republic, Ministry of Environment, Energy and Climate Change

Council of the European Communities (2007) Directive 2007/60/EC of the European Parliament and of the Council of 23 October 2007 on the Assessment and Management of Flood Risks

Daniil EI, Michas SN, Lazaridis LS (2005) Hydrologic modelling for the determination of design discharges in ungauged basins. Global Nest 7(3):296-305

de Moel H, van Alphen J, Aerts JCJH (2009) Flood maps in Europe - methods, availability and use. Nat Hazards Earth Syst Sci Discuss 9:289-301

Efstratiadis A, Koussis AD, Koutsoyiannis D, Mamassis N (2013) Flood design recipes vs. reality: can predictions for ungauged basins be trusted? Nat Hazards Earth Syst Sci Discuss 1:7387-7416

European Commission (2014) Member States' Examples of Flood Hazard and Flood Risk Maps, available at: http://ec.europa.eu/environment/water/flood risk/pdf/MS\%20 examples.pdf. Accessed 30 Jan 2015

EXCIMAP (European Exchange Circle on Flood Mapping) (2007) Handbook on Good Practices for Flood Mapping in Europe, mapping Available at: http://ec.europa.eu/environment/water/flood_risk/flood_atlas/ pdf/handbook_goodpractice.pdf. Accessed 29 Jan 2015

Koutsoyiannis D (2004) 'Research Project: 'Investigating the stability of slopes and bottom of Filothei stream using mathematical models and modern environmental techniques', Scientific Coordinator Stamou A. Vol. Hydrologic Study of floods Athens, National Technical University of Athens

Larson C. L. and B. M. Reich (1973) 'Relationship of observed rainfall and runoff recurrence intervals. In Floods and Droughts', Proc. 2nd Intern. Symp. in Hydrology, Water Resources Publ, Fort Collins, CO

McCuen RH (1998) Hydrologic Analysis and Design. (2nd ed.), Prentice Hall, Inc

Ministry of Environment, Planning and Public Works (2002a) 'Guidelines to Design and Construction Supervision', Volume 8: Irrigation-Drainage. Hydraulic Works, Athens (in greek)

Ministry of Environment, Planning and Public Works (2002b) 'Guidelines for Road Works Studies', Volume 8: Irrigation-Drainage. Hydraulic Works, Athens

(in greek)

Mpouri S (2008) Bounding of a river of small watershed without rainfall records using the programs ArcGIS, HEC-GeoRAS and HEC-RAS. Postgraduate thesis, Postgraduates Studies Program 'GeoInformatics', School of Rural and Surveying Engineering, Faculty of Engineering, Aristotle University of Thessaloniki

Papamichail D and Georgiou P (1999) Statistical analysis of the intensity-duration-frequency relationships of extreme rainfalls. Proceedings of 12th Panhellenic Statistics Conference (Greek Statistical Institute), Spetses, Greece, 455-464

Pilgrim D H and Cordery I (1993) Flood Runoff. In: Handbook of Hydrology, ed. D.R. Maidment, McGraw Hill, Inc SCS (Soil Conservation Service) (1972) Hydrology. SCS National Engineering Handbook, Section 4, U.S. Department of Agricultural, Washington, DC

Special Secretariat for Water (2012) The Implementation of Directive 2007/60/EC: Preliminary Flood Risk Assessment. Greek Republic, Ministry of Environment, Energy and Climate Change, Athens

Sutcliffe JV (1978) Methods of flood estimation, a guide to flood studies report, report 49. Institute of Hydrology, Wallingford

Tsakiris G (1995) Flood Runoff. In: Water Resources: I. Engineering Hydrology. ed. G. Tsakiris, Editions Symmetria, Athens (in greek), pp 393-423

Tsakiris G, Nalbantis I, Pistrika A (2009) Critical technical issues on the EU flood directive. Eur Water 25(26): $39-51$

U.S.B.R. (US Department of the Interior, Bureau of Reclamation) (1987) Design of small dams: a water resources technical publication. United States Department of the Interior, Bureau of Reclamation, Washington, pp 25-37

Wetsphal DA (2001) Hydrology for drainage system design and analysis. In: Stormwater collection systems design handbook. L. W. Mays (ed) McGraw-Hill 
Yannopoulos S, Eleftheriadou E, Tzivani E, Giannopoulou Io (2012) Estimation of peak discharge in a small ungauged watershed based on IDF curves and synthetic unit hydrographs. Proceedings of the XI International Conference on Protection and Restoration of the Environment, eds. K.L. Katsifarakis, N. Theodossiou, C. Christodoulatos, A. Koutsospyros, Z. Mallios, July 3-5, Thessaloniki, Greece, 156-165

Yannopoulos S, Eleftheriadou E, Mpouri S, Giannopoulou Io (2014) Hydrologic and Hydraulic Procedures for Engineering Application at Ungauged Watersheds: A Greek Case Study. Proceedings of the XII International Conference on Protection and Restoration of the Environment (eds. A. Liakopoulos, A. Kungolos, C. Christodoulatos, A. Koutsospyros), June 29 to July 3, Skiathos Island, Greece, 43-49 